\title{
Variability of dynamic capabilities in the small business development process
}

\author{
Marek Matejun * \\ Faculty of Management and Production Engineering, Lodz University of Technology, Lodz, Poland
}

\author{
Keywords \\ Resource-based view \\ Dynamic capabilities \\ organizational development \\ Small business \\ Received: 9 August 2018 \\ Accepted: 17 September 2018 \\ Published: 10 October 2018
}

\begin{abstract}
The paper aims to determine the level and scope, and nature of the variability of dynamic capabilities in the various stages of the development process of SME sector companies. The objective was achieved by conducting survey research on a sample of 356 micro, small and medium enterprises that operate in the European Union. The results indicate that the level of dynamic capabilities significantly varied in the subsequent phases, with the relatively highest values reached the stages characterized by significant development activity. Its characteristic is the polynomial nature of the course that fits the model assumptions of staged concepts of the life cycle of the organization. Therefore, the research results can be a useful tool for describing, interpreting, and forecasting the volatility level of dynamic capabilities in the development cycle of micro, small and medium-sized enterprises.
\end{abstract}

(C) 2018 The Author(s). Published by TAF Publishing.

\section{INTRODUCTION}

Resources-related limitations (especially in the sphere of tangible/financial resources) (Lonial \& Carter, 2015) and activities conducted under the conditions of intense pressure exerted by the environment (Shigang, 2010) are one of the most important features of the specificity of micro, small and medium-sized enterprises (in the article: SMEs, small business) which significantly determines the course of development of these entities. This causes a great number of managerial challenges for these companies, challenges associated with the development and exploitation of the available resources.

The resource-based theory, which emphasises the growing importance of resources (mostly intangible) in business management, provides interesting conclusions in this respect. One of the most important proposals within the framework of this theory is the concept of resource-based dynamic capabilities aimed at the sensing, seizing and transforming of resources under the conditions of strong volatility of the environment in order to strengthen the unique strategic characteristics of the resource base, build a sustainable competitive advantage and improve market performance (D. Teece, 2007). Previous studies indicate that the resource potential of the SME sector companies differs significantly in the subsequent stages of their development cycle (Ferreira, Azevedo, \& Cruz, 2011). In the current literature, however, there is no analysis of variability of dynamic capabilities in the development cycle of micro, small and medium-sized enterprises, which is an important research gap, and at the same time an inspiration to undertake research within the framework of this study.

Taking this into account, the paper aims to determine the level as well as the extent and nature of variability of resource-based dynamic capabilities in the individual stages of SMEs' development cycle. Thus, the subject of the research is variability of dynamic capabilities in the small business development process. In terms of the subjective approach, the study was conducted on a random sample of 356 SMEs that operate in the European Union.

The structure of the paper is as follows: literature review, research methodology and presentation of results. The final part presents limitations and future directions of research, followed by conclusions. The results obtained indicate that the level of resource-based dynamic capabilities differs sig-

\footnotetext{
${ }^{*}$ corresponding author: Marek Matejun

†email: matejun@p.lodz.pl
} 
nificantly in the individual phases, and reaches relatively the highest values for the stages characterized by considerable development activity. This level is characterized by the polynomial nature of the course of development, matching the model assumptions of the concept describing the staged organizational life cycle. The presented study was conducted as a preliminary analysis carried out under the research project no. 2015/17/B/HS4/00988 financed by the National Science Centre, Poland.

\section{LITERATURE REVIEW}

Micro, small and medium-sized enterprises are the most numerous category of entities in the modern market economy and are identified in principle in all the countries in the world on the basis of specific qualitative and quantitative criteria (Ayyagari, Demirgüç-Kunt, \& Beck, 2003; Bizon, 2016). Their limited internal capacity and high sensitivity to external conditions mean that the management of these entities often needs to fulfil higher requirements than in the case of large companies. Any errors in this area may very severely and adversely affect the operations of SMEs (Bernik, Azis, Kartini, \& Harsanto, 2015; Griffin, 2017), and due to the use of simplified organizational and legal forms, these errors can frequently yield negative administrative and legal consequences for owners of these entities and their families.

The importance of applying effective methods of resource management determining SMEs' success is also pointed out by Krupski (2011). The results of his research indicate that the resource-based approach is the dominant formula of the strategic orientation in the functioning of the smallest business entities, affecting at the same time their level of flexibility, scale of exploitation of business opportunities and ability to avoid market risks. The resource-based theory provides valuable conclusions in this area for SMEs by emphasising that the position and competitive advantage are built not by the amount of available/controlled resources, but through their effective use and the development of certain strategic features of the resource base (Barney \& Hesterly, 2015; Boonvut, 2017). These features include: the value which allows to reduce market risk, uniqueness in the environment, the difficulty in imitation by competitors and in their access to substitutes or alternative solutions, as well as a high level of ability to organize and control the company's resource base.

The concept of dynamic capabilities, which indicates what actions and routine-based activities in terms of search, acquisition, transformation and use of resources should be taken in order to effectively build a strong market posi- tion and a sustainable competitive advantage of the company under the conditions of high volatility of the environment, plays an important role in the creation of the resource potential (D. Teece, 2009). Dynamic capabilities literature makes a conceptual distinction between ordinary capabilities and dynamic capabilities. While ordinary capabilities determine how a firm operates at the moment and ensure operational effectiveness, dynamic capabilities enable the firm to change, sensing and seizing new business opportunities as well as create opportunities for new strategies through modifying ordinary capabilities (Laaksonen \& Peltoniemi, 2018).

Therefore, the dynamic of these capabilities derives from their change-oriented nature and they can be disaggregated into three interrelated (Wilden \& Gudergan, 2015) actions: sensing, seizing, and reconfiguring. Sensing involves activities of scanning, search, and exploration aimed at gathering information and learning about market and entrepreneurial opportunities. Seizing includes the evaluation of existing and emerging capabilities/opportunities aimed at making investments in tangible and intangible assets. Finally, reconfiguration encompasses activities that recombine bundles of resources and ordinary capabilities in order to achieve synergistic complementarities inside and outside the enterprise (Fainshmidt \& Frazier, 2017). Other, more complex classifications of dynamic capabilities include (Salunke, Weerawardena, \& McColl-Kennedy, 2011; D. J. Teece, 2014)

- The capability to identify and recognise the potential of the environment and to assess market opportunities and risks. - The capability to mobilise resources depending on the situation and to appropriately exploit emerging market opportunities.

- The capability to reconfigure the set of resources available and adapt to changing conditions by introducing required changes in the structure of resources and the scope of business activity conducted.

- The capability to renew the resource base of the company in accordance with current trends and requirements imposed by competitors.

- The capability to protect resources in order to ensure an adequate level of strategic characteristics of the company's resource base.

- The capability to configure and coordinate resources for effective and efficient implementation of the company's strategic objectives.

- The capability to purchase and acquire valuable resources from the environment,.

- The capability to strengthen and expand the resource base 
depending on the market situation as well as the current and future needs of the company.

Laaksonen and Peltoniemi (2018) draw attention to a lack of unambiguous and generally accepted principles of operationalization and measurement of dynamic capabilities in research practice of management sciences. Based on their own research on a sample of 232 operationalizations of dynamic capabilities in global research practice, the researchers distinguish four practical approaches to their measurement: (1) measurement based on assessments of managers and business owners, (2) measurement based on financial data, (3) measurement expressed through past experience and achievements of enterprises, and (4) measurement based on managers' or employees' experience, actions and performance. Due to the fact that the first approach to measurement of dynamic capabilities is dominant (identified in $67 \%$ of operationalizations under analysis), the study adopts the type of measurement based on assessments of mangers of the SME sector companies. For this purpose, the operationalization based on one-dimensional indicators, which despite its limitations is successfully applied in research practice e.g., (Pervan, Curak, \& Pavic Kramaric, 2018), was used.

Results of many studies so far have confirmed a positive impact of dynamic capabilities on the performance and scope of SMEs' market activity (Mudalige, 2015; Rice, Liao, Galvin, \& Martin, 2015), on the level of SMEs' internal and open innovation (Nolsøe Grünbaum \& Stenger, 2013; Grimaldi, Quinto, \& Rippa, 2013; Ripain, Amirul, \& Mail, 2017), as well as on SMEs' proactive posture and capability to integrate resources in recognising new opportunities in an environment characterized by high volatility and uncertainty (Battisti \& Deakins, 2017; Halim, Adnan, \& Khusaini, 2017). An important contribution to the development of the theory and practice of dynamic capabilities was also made by studies conducted by Polish authors. These include: identifying the place of dynamic capabilities in a broader perspective of organizational capabilities (Sta 'n czy Hugiet, Pi ó rkowska, \& Sta 'n czyk, 2016; Wójcik-Karpacz, 2017), drawing attention to the role of imovations (Krzakiewicz \& Cyfert, 2016) and relational competences (Zakon, 2008) in the process of shaping dynamic capabilities of the organization, identification and assessment of dynamic capabilities in the value appropriation process (Najda, 2016), as well as an indication of the role of dynamic capabilities in the evolution of organizational routines (Karpacz, 2013).

One of the areas of variability of dynamic capabilities can be a variety of changes that occur in the development cycle of an enterprise. This cycle in the theory of management sciences is normally described by using staged models expressing transformations taking place in organizations associated with the transition through the subsequent stages of development characterized by a significantly different nature and quantitative and/or qualitative characteristics. A number of various staged models of the development cycle of an enterprise are formulated in the literature (Levie \& Lichtenstein, 2010), some of which are adjusted to the specificity of SMEs by:

- Expanding the initial (start-up) phase by incorporating the conceptual stage in which a business plan for the new company is developed (Felsenstein \& Schwartz, 1993).

- Taking into consideration the dominant role of entrepreneurship and owners' attitude as the key factors determining success in the small business development cycle (Adizes, 1988).

- Rejecting the deterministic course of the development cycle allowing both the return to the initial phases (Lewis \& Churchill, 1983) as well as the rapid growth with bypassing the intermediate phases (Granlund \& Taipaleenmäki, 2005).

- Drawing attention to the possibility of using significant developmental changes to prevent crisis phenomena and effectively prolong the company's life span (Belussi \& Sedita, 2009).

- Taking into account the possibility of leaving the category of SMEs by separating ownership and management, or by a merger with another company, aimed at the further expansion in the category of large enterprises (Jones, 2015).

Based on the existing development cycle literature, an original stage dynamics and statics model of SMEs' development-cycle was proposed. It covers 8 stages relating to specificity of small business (Matejun \& Mikoláš, 2017; Marfa, Niguidula, \& Enriquez, 2017).

- The pre-emergence stage of conceptual nature, aimed at making a decision about setting up the company.

- The emergence stage, in which first investments and first attempts at developing and commercializing the company's market offer based on entrepreneurial activity are made.

- The survival stage, which is a period of the first market verification of the company and of a challenge related to ensuring the required level of profitability and liquidity.

- The dynamic growth stage, in which the following quantitative growth indicators significantly increase: turnover, the level of employment or the number of contractors, accompanied by the introduction of proactive qualitative changes in the company.

- The separation and expansion stage, in which important expansion activities in the area of market, product or in 
vestment are carried out, and the authority is often passed into the hands of professional managers.

- The stabilization stage, in which the dynamics of business growth is reduced, accompanied by stabilization of financial indicators, reduction in investment and growth of the organization.

- The revitalization stage, characterized by a dynamic and proactive approach to the company's further development based on the introduction of significant changes in the company's structure, business strategy and market offer.

- The decline stage, characterized by a rather permanently reduced level of efficiency and effectiveness, as well as negative financial results, which may lead to the collapse of the company.

Some of the stages in the proposed model are characterized by a proactive approach to business activity and focusing efforts on market, investment and development processes. Such stages are set out in the model as the dynamic development stages and include: the emergence stage, the dynamic growth stage, the separation and expansion stage and the revitalization stage. Their opposites are the static stages, characterized by more conservative and stable actions focused on current activities and ensuring the continuity of the company. These stages include: the pre-emergence stage, the survival stage, the stabilization stage and the decline stage.

Although development cycle models are sometimes criticized, including the allegations of a too excessively deterministic course or a lack of precision in defining the individual phases (Phelps, Adams, \& Bessant, 2007), it seems, however, that they can be a valuable tool for description, interpretation and prediction of variability of dynamic capabilities in the processes of SMEs' development. The subsequent part of this paper is devoted to the empirical analysis of this issue.

\section{METHODOLOGY OF RESEARCH AND CHARACTERISTICS OF THE RESEARCH SAMPLE}

The survey conducted on a random sample of 356 SME sector companies that operate in the European Union, including: 235 (66\%) micro, 89 (25\%) small and 32 (9\%) medium-sized enterprises, served to achieve the objective of the paper. The size of the entities was identified on the basis of the criteria of the number of full-time employees, the size of revenue and the balance sheet value in accordance with the rules of the formal definition of SMEs in force in the European Union (Berisha \& Pula, 2015, pp. 18-20). The study also encompassed only autonomous companies whose capital and/or ownership ties with other entities did not exceed $25 \%$.
Most of the analyzed enterprises operate in the form of sole proprietorship (55\%) or limited liability companies (24\%). The studied companies were most active in the service sector $(69 \%)$, especially in such industries as construction and architecture (9\%), information technology and communication (8\%), education and training (8\%), management consulting, professional services, mainly legal or tax services (7\%), as well as financial and insurance services (6\%). Entities active in the market for more than 20 years (31\%) or operating for 5-10 years (29\%) dominated in the sample. The scope of activities of the analyzed companies is rather wide - almost $70 \%$ entities declare operations at least at the national level.

The surveyed respondents comprised representatives of the analyzed entities and their opinions were used to gather empirical material. They were mostly company owners/coowners $(65 \%)$, less often senior managers $(22 \%)$ or employees authorized and legitimized by the management to participate in the study (13\%). The questions were responded mostly by men (42\%), those aged 31 to 50 years $(60 \%)$ and over 50 years (29\%), with a higher education in the (84\%) technical (36\%), economic (31\%), humanistic $(9 \%)$ or scientific $(7 \%)$ field.

\section{RESEARCH RESULTS}

First, the range of occurrence of the individual phases of the development cycle in the analyzed sample was identified. This was done on the basis of the opinions of the respondents indicating in the survey questionnaire at which stage of the development cycle their company was. In order to increase the precision and objectivity of the responses, each phase was supplemented with a short descriptive characteristics so that respondents could provide an answer which corresponded well to the organizational reality. The results indicate that the surveyed enterprises are primarily in the phase of stabilization or dynamic growth, and the range of dynamic phases increases to a small extent along with the size of the surveyed entities, $r_{s}(n=356)=0.15, p<0.01$. Since only actually operating enterprises participated in the study, no entities in the pre-emergence stage were identified. Due to the relatively long period of market activity of the analyzed companies, only 4 respondents indicated the phase of emergence. Relatively few indications also concerned the phase of separation and expansion, which confirms the aspirations of owners of the SME sector companies to fully control their enterprises and their reluctance to transfer power into the hands of hired managers. A detailed scope of the occurrence of the individual phases of the development cycle in the analyzed sample is presented in Table 1. 
TABLE 1. The level of dynamic capabilities of the analyzed companies

\begin{tabular}{|c|c|c|c|c|c|c|c|c|}
\hline \multirow[t]{2}{*}{ Development Cycle Phases } & \multicolumn{2}{|c|}{ Total in the Sample } & \multicolumn{6}{|c|}{ Companies by Size } \\
\hline & $\mathbf{n}$ & $\%$ & $\mathbf{n}$ & $\%$ & $\mathbf{n}$ & $\%$ & $\mathbf{n}$ & $\%$ \\
\hline Emergence stage & 4 & $1 \%$ & 4 & $2 \%$ & 0 & $0 \%$ & 0 & $0 \%$ \\
\hline Survival stage & 53 & $15 \%$ & 42 & $18 \%$ & 10 & $11 \%$ & 1 & $3 \%$ \\
\hline Dynamic growth stage & 101 & $29 \%$ & 58 & $24 \%$ & 30 & $34 \%$ & 13 & $41 \%$ \\
\hline Separation and expansion stage & 12 & $3 \%$ & 4 & $2 \%$ & 7 & $8 \%$ & 1 & $3 \%$ \\
\hline Stabilization stage & 112 & $32 \%$ & 75 & $32 \%$ & 2 & $528 \%$ & 12 & $37 \%$ \\
\hline Revitalization stage & 51 & $14 \%$ & 32 & $13 \%$ & 14 & $16 \%$ & 5 & $16 \%$ \\
\hline Decline stage & 23 & $6 \%$ & 20 & $9 \%$ & 3 & $3 \%$ & 0 & $0 \%$ \\
\hline Static stages in total & 188 & $53 \%$ & 137 & $58 \%$ & 38 & $43 \%$ & 13 & $41 \%$ \\
\hline Dynamic stages in total & 168 & $47 \%$ & 98 & $42 \%$ & 51 & $57 \%$ & 19 & $59 \%$ \\
\hline Total in the sample & 356 & $100 \%$ & 235 & $100 \%$ & 89 & $100 \%$ & 32 & $100 \%$ \\
\hline
\end{tabular}

(Source: own elaboration based on the results of the survey)

Next, the assessment of dynamic capabilities in the analyzed sample was conducted. The level of individual dynamic capabilities was evaluated relatively, in relation to the main competitors, on a scale from 1 (much worse than the competitors) to 7 (much better than the competitors). In the survey questionnaire, each dynamic capability was accompanied by a short commentary that helped the respondents to provide answers well corresponding to the organizational reality. The results are presented as the Mean (M) and Median (Me) of the responses. They indicate that the dynamic capabilities of the analyzed entities are generally somewhat better developed than in the case of their competitors (response mean of approx. 4.50). The level increases significantly statistically to a small extent depending on the size of the analyzed companies, $r_{s}(n=356)=0.18$, $p<0.01$. It is not, however, significantly differentiated depending on the age of the companies, $r_{s}(n=356)=-0.08, p$ $>0.05$, or their scope of market activity, $r_{s}(n=356)=0.07$, $p>0.05$. Detailed results of the level of dynamic capabilities in the analyzed sample are shown in Table 2.

TABLE 2. The level of dynamic capabilities of the analyzed companies

\begin{tabular}{|c|c|c|c|c|c|c|c|c|}
\hline \multirow[t]{2}{*}{ Development capabilities } & \multicolumn{2}{|c|}{ Total in the Sample } & \multicolumn{6}{|c|}{ Companies by Size } \\
\hline & $M$ & ME & $M$ & ME & $M$ & ME & $M$ & ME \\
\hline Total dynamic capabilities, including the ability & 4.62 & 4.50 & 4.51 & 4.38 & 4.76 & 4.75 & 5.09 & 4.94 \\
\hline To identify and evaluate market opportunities & 4.48 & 4.00 & 4.33 & 4.00 & 4.69 & 4.00 & 5.00 & 5.00 \\
\hline To mobilize resources & 4.86 & 5.00 & 4.75 & 5.00 & 4.99 & 5.00 & 5.31 & 5.00 \\
\hline To reconfigure and adapt resources & 4.75 & 5.00 & 4.66 & 5.00 & 4.83 & 5.00 & 5.13 & 5.50 \\
\hline To renew the resource base of the company & 4.57 & 4.00 & 4.51 & 4.00 & 4.61 & 4.00 & 4.91 & 5.00 \\
\hline To protect resources & 4.59 & 4.00 & 4.50 & 4.00 & 4.71 & 5.00 & 4.91 & 5.00 \\
\hline To configure and coordinate resources & 4.67 & 5.00 & 4.54 & 4.00 & 4.79 & 5.00 & 5.34 & 5.00 \\
\hline To purchase and acquire resources & 4.39 & 4.00 & 4.25 & 4.00 & 4.58 & 5.00 & 4.94 & 5.00 \\
\hline To strengthen and expand resources & 4.65 & 5.00 & 4.51 & 4.00 & 4.87 & 5.00 & 5.13 & 5.00 \\
\hline
\end{tabular}

(Source: own elaboration based on the results of the survey)

The respondents pointed to the ability to mobilise resources and the ability to reconfigure and adapt resources, which is associated with a relatively high level of flexibility in SMEs' operations, as to the comparatively more developed dynamic capabilities. On the other hand, the ability to purchase and acquire resources from the environment, which is associated with resource-based limitations of these smallest operators and their low bargaining power in relations with market partners, was rated relatively lower.

The coefficient of variation for the results obtained indicates approx. $20 \%$ of the dispersion of dynamic capabilities around the mean, which applies, however, mainly to micro and small companies, as for medium-sized enterprises the dispersion decreases to $V=17 \%$. The ability to purchase and acquire resources $(V=28 \%)$ and the ability to renew the resource base of the company $(V=27 \%)$ obtained the relatively highest level of variation of the evaluations provided. Further analyses were focused on the identification and measurement of the level and variation of dynamic capabilities in SMEs' development cycle. Table 2 shows the detailed results for the evolution of the analyzed capabilities depending on the phase of the development cycle of the studied entities. 
TABLE 3. Dynamic capabilities in the development cycle of the analyzed SMEs

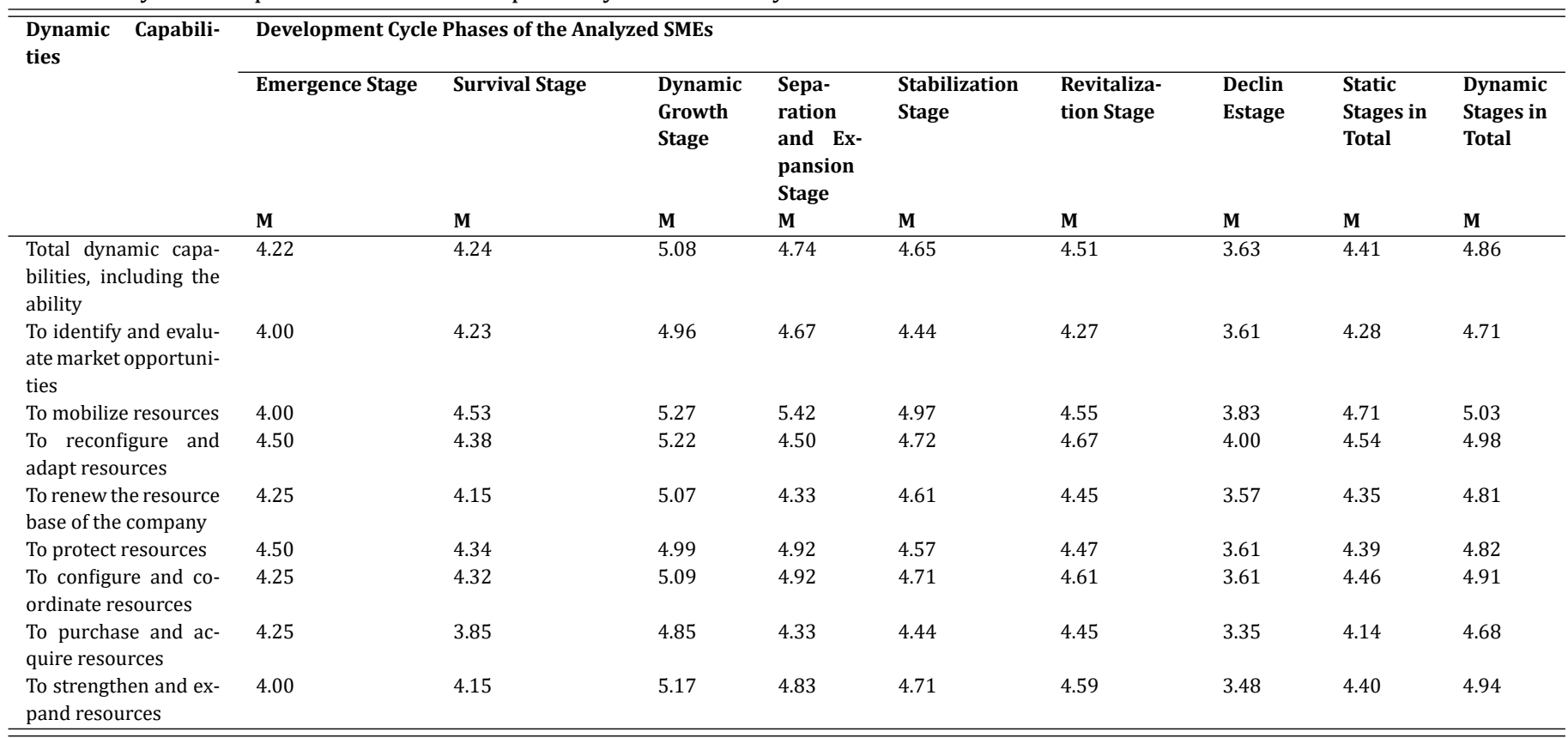

(Source: own elaboration based on the results of the survey)

The results obtained indicate that in the initial phase dynamic capabilities are developed at a relatively low level, although this level is higher than the average. Their level then rises to quite a high level in the dynamic growth phase and decreases slightly in the remaining phases related to making significant developmental changes. Interestingly, a relatively high level of dynamic capabilities was identified in the stabilization phase. This indicates that the studied companies have to devote a large amount of resource-based effort in this phase in order to maintain the achieved competitive position. The relatively lowest level of dynamic capabilities occurs in the decline phase, as this phase indicates serious problems and crisis phenomena threatening the continued functioning of the company.

Based on the results obtained, a graphic evaluation and interpretation of the level of dynamic capabilities in the development cycle of the studied companies was made. The results indicate a polynomial line of this variation, characterized by 4 fluctuations. For this reason, an order 5 polynomial trendline was used to assess the level of fit of the results obtained. The equation for this line obtained using the method of least squares is of the form: $y=-0.02 x^{5}+0.32 x^{4}$ $-2.39 x^{3}+8.11 x^{2}-11.82 x+10.01$. The level of fit of the line measured with the coefficient of determination is 0.97 , which indicates a very high level of fit of the results obtained to the model data. At the same time, further analyses based on other approaches to determining the trendline showed a significantly smaller fit:
- In the case of exponential type: $R^{2}=0.09$

- In the case of linear type: $R^{2}=0.08$.

- In the case of logarithmic type: $R^{2}=0.004$

- In the case of power type: $R^{2}=0.01$.

The analysis of distribution of the "dynamic capabilities" variable in the sample, measured with the use of the Shapiro-Wilk test of normality, showed the absence of normality of distribution, $\mathrm{W}(d f=356)=0.98, p<0.01$. For this reason, non-parametric tests were used to assess variability in the level of dynamic capabilities in individual phases of the life cycle: the Mann-Whitney $U$ test (to compare dynamic capabilities in 2 phases) and the Kruskal Wallis $H$ Test (to compare dynamic capabilities in more than 2 phases).

Analyses carried out with the use of the Kruskal Wallis $\mathrm{H}$ Test showed that the level of dynamic capabilities differed significantly in the life cycle of the SME sector companies, $H(6, n=356)=61.93, p<0.01$. Subsequent analyses indicated:

- A significantly higher level of dynamic capabilities in the dynamic phases of the life cycle of companies in the SME sector compared to the statistic phases, $U=11321.00, Z=$ $-4.62, p<0.01$.

- Lack of significant differences in the level of dynamic capabilities between (1) the emergence stage and (2) the survival stage, $U=99.00, Z=-0.22, p>0.05$.

- Lack of significant differences in the level of dynamic capabilities between (4) the separation and expansion stage, 
(5) the stabilization stage and (6) the revitalization stage, $H$ $(3, n=356)=1.77, p>0.05$.
A detailed course of the analyzed polynomial trendline is shown in Figure 1.

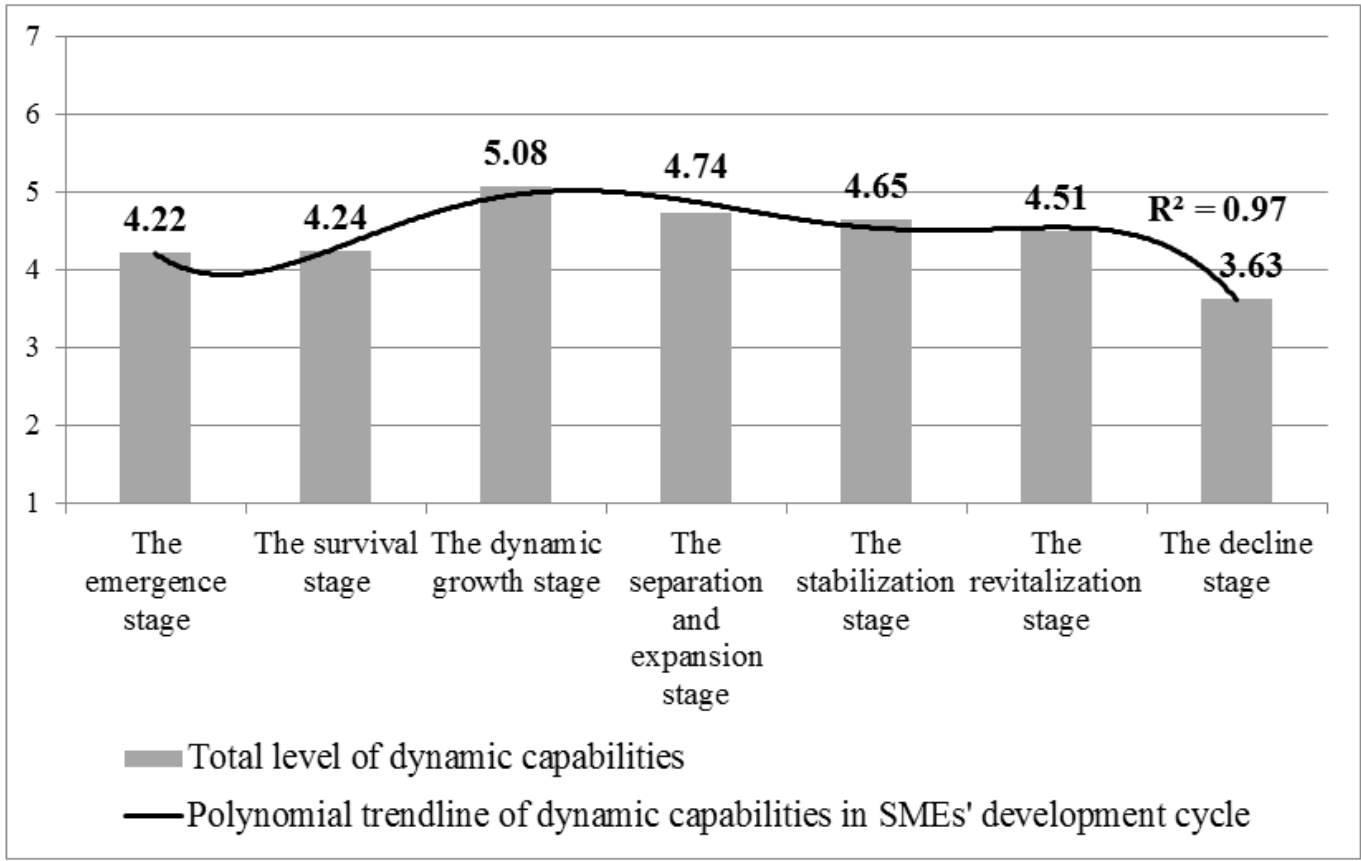

FIGURE 1. Dynamic capabilities in the development cycle of the surveyed SMEs

In general, this confirms significant developmental variation of dynamic capabilities in the development cycle of the surveyed SMEs. The range of this variation is approx $40 \%$ and ranges from the level lower than the average at the decline phase to a relatively high level in the dynamic growth phase of the company. This variation is also polynomial and its shape corresponds to the model assumptions of staged models in the life cycle of an enterprise. It can be expected that the intensification of activities of the company during the period of stabilization or the phase of significant developmental changes in terms of dynamic capabilities can contribute to the company's entry onto the path of further dynamic growth, instead of following the direction of the decline of business activity (in the event of the occurrence of adverse events).

\section{LIMITATIONS AND FUTURE DIRECTIONS OF RESEARCH}

Considering the results obtained and formulating conclusions based on these findings, the limitations of the conducted research should be taken into account. These limitation mainly result from the application of the inductive research approach (Popper, 2014) as well as the use of survey research as the research method (Nardi, 2018). This is associated, first of all, with high subjectivism of respondents' opinions as well as differences in interpretation and individual perception of the issues under consideration.
The declarative nature of responses is also a problem, as it does not guarantee that the analyzed enterprises are actually in the phases of the life cycle indicated or represent the assumed level of dynamic capabilities. The use of onedimensional indicators to describe complex economic reality and a lack of consideration of the broader time context of the carried out analyses can also be considered as limitations. Since the research was only quantitative, it was also not possible to apply research triangulation, which is becoming one of key methodological trends in management sciences (Cameron, Sankaran, \& Scales, 2015).

The identified weaknesses also provide indications as to further research directions. These include, first of all, the analysis of mediators and moderators of relationships between the level of dynamic capabilities and the phases of the life cycle of companies in the SME sector. It is also important to identify resource-related factors determining the company's transition to the subsequent development phases. In methodological terms, it is worth considering, first of all, the use of triangulation in further research. It seems particularly essential to combine quantitative methods with qualitative methods (including the case study method), allowing for a deeper exploration of the organizational reality and formulation of more insightful conclusions based on a synergistic linkage of quantitative and qualitative results. 


\section{CONCLUSION \& IMPLICATIONS}

The results obtained indicate that dynamic capabilities in the analyzed sample are developed at a moderate level, but increase with the growth of the enterprises, reaching a fairly high level in the medium-sized enterprises surveyed. One of the factors of their variation is the organizational development cycle which is associated with the occurrence of significantly different stages characterized by specific developmental characteristics. This variation follows the polynomial course corresponding to the model assumptions of the concept of the life cycle of an enterprise.

In the initial phases of business activity (the emergence and the survival stages), resource-based dynamic capabilities are developed at a relatively lower level. This is related to the smaller size of business activity as well as to the relatively poor development of relational and market resources that are usually developed over an extended period of economic activity. The entry of the company into a period of dynamic growth intensifies the level of dynamic capabilities in connection with the need to manage the dynamically growing resource base which is often characterized by a more expanded scope of strategic features that create a competitive advantage of a given entity. The inability to permanently increase the size of business activity leads to the stabilization period or causes the need for significant developmental changes (the revitalization stage), resulting often in leaving the category of SMEs and moving on to the category of large enterprises (the separation and expansion stage). In all these cases, the level of dynamic capabilities decreases, as companies need to focus on other types of activity, securing their interests in the long term. The occurrence of crisis phenomena and the entry into the decline phase of activity causes further reduction in the level dynamic capabilities, which is related to the diminishing resource potential of a given business entity.

The nature of the identified phenomena indicates a close relationship between SMEs' development processes and the involvement of these entities in activities aimed at the acquisition, transformation and use of resources in their business activity. The research results can therefore be a useful tool for description, interpretation and forecasting of the volatility level of dynamic capabilities in the development cycle of micro, small and medium-sized enterprises.

\section{REFERENCES}

Adizes, I. (1988). Corporate lifecycles: How and why corporations grow and what to do about it. Englewood Cliffs, NJ: Prentice-Hall.

Ayyagari, M., Demirgüç-Kunt, A., \& Beck, T. (2003). Small and medium enterprises across the globe: A new database. New York, NY: The World Bank.

Barney, J., \& Hesterly, W. (2015). Strategic management and competitive advantage: Concepts and cases. Boston, MA: Pearson Education Limited.

Battisti, M., \& Deakins, D. (2017). The relationship between dynamic capabilities, the firm's resource base and performance in a post-disaster environment. International Small Business Journal, 35(1), 78-98. doi:https://doi.org/10.1177/ 0266242615611471

Belussi, F., \& Sedita, S. R. (2009). Life cycle vs. multiple path dependency in industrial districts. European Planning Studies, 17(4), 505-528. doi:https://doi.org/10.1080/09654310802682065

Bernik, B., Azis, Y., Kartini, D., \& Harsanto, B. (2015). Managing innovation of SMEs in creative industry for interactive game subsector and TV and Radio subsector based on local wisdom in development of competitiveness business (Case Study SMEs in Bandung). International Journal of Business and Administrative Studies, 1(2), 49-53. doi:https://doi.org/ 10.20469/ijbas.10001-2

Bizon, W. (2016). Stimulating entrepreneurship by introducing behavioural incentives, propensity to use financial instruments in the context of decision makers' personal characteristics and their financial knowledge in Polish SMEs. Journal of Administrative and Business Studies, 2(6), 270-279. doi:https://doi.org/10.20474/jabs-2.6.2

Boonvut, S. (2017). The quality financial statements of Small and Medium Enterprises Business (SME's) in view of the tax auditor. International Journal of Business and Economic Affairs, 2(6), 335-340. doi:https://doi.org/10.24088/ ijbea-2017-26002

Cameron, R., Sankaran, S., \& Scales, J. (2015). Mixed methods use in project management research. Project Management Journal, 46, 90-104. doi:https://doi.org/10.1002/pmj.21484

Fainshmidt, S., \& Frazier, M. (2017). What facilitates dynamic capabilities? The role of organizational climate for trust. Long Range Planning, 50(5), 550-566. doi:https://doi.org/10.1016/j.lrp.2016.05.005 
Felsenstein, D., \& Schwartz, D. (1993). Constraints to small business development across the life cycle: Some evidence from peripheral areas in Israel. Entrepreneurship and Regional Development, 5(3), 227-246. doi:https://doi.org/10.1080/ 08985629300000014

Ferreira, J. J. M., Azevedo, S. G., \& Cruz, R. P. (2011). SME growth in the service sector: A taxonomy combining lifecycle and resource-based theories. The Service Industries Journal, 31(2), 251-271. doi:ttps://doi.org/10.1080/ 02642060802712855

Granlund, M., \& Taipaleenmäki, J. (2005). Management control and controllership in new economy firms-a life cycle perspective. Management Accounting Research, 16(1), 21-57. doi:https://doi.org/10.1016/j.mar.2004.09.003

Griffin, R. (2017). Management. Boston, MA: Cengage Learning.

Grimaldi, M., Quinto, I., \& Rippa, P. (2013). Enabling open innovation in small and medium enterprises: A dynamic capabilities approach. Knowledge and Process Management, 20(4), 199-210. doi:https://doi.org/10.1002/kpm.1423

Halim, N. H. A., Adnan, A. N., \& Khusaini, N. S. (2017). Kaizen event assessment through performance and economic investment analysis. International Journal of Business and Administrative Studies, 3(1), 1-8. doi:https://doi.org/10.20469/ ijbas.3.10001-1

Jones, N. (2015). Sme's life cycle-steps to failure or success? AU-GSB e-Journal, 2(2), 3-14.

Karpacz, J. (2013). Procedures as a tool to consolidate recurrent patterns of employees' behavior. Journal of Management and Finance, 4(2), 171-180.

Krupski, R. (2011). Development of small and medium-sized enterprises in the light of empirical research: The strategic contex. In S. Lachiewicz \& M. Matejun M. (Eds.), Management of small and medium-sized enterprises development. Warsaw, Germany: Oficyna a Wolters Kluwer business.

Krzakiewicz, K., \& Cyfert, S. (2016). Imovation in shaping dynamic capabilities of organisations. Management, 20(2), 8-22. doi:https://doi.org/10.1515/manment-2015-0047

Laaksonen, O., \& Peltoniemi, M. (2018). The essence of dynamic capabilities and their measurement. International Journal of Management Reviews, 20(2), 184-205. doi:https://doi.org/10.1111/ijmr.12122

Levie, J., \& Lichtenstein, B. B. (2010). A terminal assessment of stages theory: Introducing a dynamic states approach to entrepreneurship. Entrepreneurship Theory and practice, 34(2), 317-350. doi:https://doi.org/10.1111/j.1540-6520 .2010.00377.x

Lewis, V. L., \& Churchill, N. C. (1983). The five stages of small business growth. Harvard Business Review, 61(3), 30-50.

Lonial, S. C., \& Carter, R. E. (2015). The impact of organizational orientations on medium and small firm performance: A resource-based perspective. Journal of Small Business Management, 53(1), 94-113. doi:https://doi.org/10.26618/ ojip.v4i1.80

Marfa, M. A., Niguidula, J. D., \& Enriquez, J. B. (2017). Business analytics in performance assessment of food manufacturing system. International Journal of Business and Economic Affairs, 2(2), 159-164. doi:https://doi.org/10.24088/ijbea -2017-22009

Matejun, M., \& Mikoláš, Z. (2017). Small business life cycle: Statics and dynamics (s\&d) model. Engineering Management in Production and Services, 9(4), 48-58. doi:https://doi.org/10.1515/emj-2017-0030

Mudalige, D. (2015). A dynamic capabilities perspective of internationalization and performance of SMEs in South Asia: A conceptual framework. International Journal of Information Technology and Business Management, 35(1), 44-62. doi:https://doi.org/10.1007/s10843-018-0239-2

Najda, J. M. (2016). Dynamic capability-based approach to value appropriation. Krakow, Poland: Jagiellonian University Press.

Nardi, P. (2018). Doing survey research: A guide to quantitative methods. Abingdon, UK: Routledge.

Nolsøe Grünbaum, N., \& Stenger, M. (2013). Dynamic capabilities: Do they lead to innovation performance and profitability? IUP Journal of Business Strategy, 10(4), 34-67.

Pervan, M., Curak, M., \& Pavic Kramaric, T. (2018). The influence of industry characteristics and dynamic capabilities on firms' profitability. International Journal of Financial Studies, 6(1), 4-10. doi:https://doi.org/10.3390/ijfs6010004

Phelps, R., Adams, R., \& Bessant, J. (2007). Life cycles of growing organizations: A review with implications for knowledge and learning. International Journal of Management Reviews, 9(1), 1-30. doi:https://doi.org/10.1111/j.1468-2370 .2007.00200.x 
Popper, K. (2014). The logic of scientific discovery. Eastford, UK: Martino Fine Books.

Rice, J., Liao, T.-S., Galvin, P., \& Martin, N. (2015). A configuration-based approach to integrating dynamic capabilities and market transformation in small and medium-sized enterprises to achieve firm performance. International Small Business Journal, 33(3), 231-253. doi:https://doi.org/10.1177/0266242613495035

Ripain, N., Amirul, S. M., \& Mail, R. (2017). Financial literacy and SMEs' potential entrepreneurs: The case of Malaysia. Journal of Administrative and Business Studies, 3(2), 60-68. doi:https://doi.org/10.20474/jabs-3.2.1

Salunke, S., Weerawardena, J., \& McColl-Kennedy, J. (2011). Towards a model of dynamic capabilities in innovationbased competitive strategy: Insights from project-oriented service firms. Industrial Marketing Management, 40(8), 1251-1263. doi:https://doi.org/10.1016/j.indmarman.2011.10.009

Shigang, Y. (2010). Competitive strategy and business environment: The case of small enterprises in china. Asian Social Science, 6(11), 64-76. doi:https://doi.org/10.5539/ass.v6n11p64

Sta 'n czy Hugiet, E., Pi ó rkowska, K., \& Sta 'n czyk, S. (2016). we have an organizational ability. In Conference on Management Forum, Wroclaw, Poland.

Teece, D. (2007). Explicating dynamic capabilities: The nature and microfoundations of (sustainable) enterprise performance. Strategic Management Journal, 28(3), 1319-1350. doi:https://doi.org/10.1002/smj.640

Teece, D. (2009). Dynamic capabilities and strategic management: Organizing for innovation and growth. Oxford, UK: Oxford University Press.

Teece, D. J. (2014). The foundations of enterprise performance: Dynamic and ordinary capabilities in an (economic) theory of firms. Academy of Management Perspectives, 28(4), 328-352. doi:https://doi.org/10.5465/amp.2013.0116

Wilden, R., \& Gudergan, S. (2015). The impact of dynamic capabilities on operational marketing and technological capabilities: Investigating the role of environmental turbulence. Journal of the Academy of Marketing Science, 43(2), 181-199. doi:https://doi.org/10.1007/s11747-014-0380-y

Wójcik-Karpacz, A. (2017). Dynamic capabilities versus operational capabilities. Organization and Management, 1(175), 51-70.

Zakon, W. (2008). Dynamic competencies in strategic management research. In R. Krupski (Ed.), Strategic managementfundamental issues. Walbrzych, Poland: Prace Naukowe. 